Article

\title{
Ionic Liquids as Additives of Coffee Bean Oil in Steel-Steel Contacts
}

\author{
James Grace ${ }^{1}$, Solomiya Vysochanska ${ }^{1}$, Jeffrey Lodge ${ }^{2}$ and Patricia Iglesias ${ }^{1, *}$ \\ 1 Mechanical Engineering Department, Rochester Institute of Technology, \\ Kate Gleason College of Engineering, Rochester, NY 14623, USA; \\ E-Mails: jhg7983@rit.edu (J.G.); sxv9719@rit.edu (S.V.)
}

2 Biotechnology and Molecular Bioscience, Rochester Institute of Technology, Thomas Gosnell School of Life Sciences, Rochester, NY 14623, USA; E-Mail: jslsbi@rit.edu

* Author to whom correspondence should be addressed; E-Mail: pxieme@rit.edu; Tel.: +1-585-475-7694; Fax: +1-585-475-7710.

Academic Editors: Antolin Hernández Battez and Rubén González Rodríguez

Received: 2 September 2015 / Accepted: 21 October 2015 / Published: 28 October 2015

\begin{abstract}
Environmental awareness and ever-growing restrictive regulations over contamination have increased the need for more environmentally-friendly lubricants. Due to their superior biodegradability and lower toxicity, vegetable oils are a good alternative to replace currently-used mineral oils. However, vegetable oils show low oxidation and thermal stability and poor anti-wear properties. Most of these drawbacks can be attenuated through the use of additives. In the last decade, ionic liquids have emerged as high-performance fluids and lubricant additives due to their unique characteristics. In this study, the tribological behavior of two phosphonium-based ionic liquids is investigated as additives of coffee bean oil in steel-steel contact. Coffee bean oil-ionic liquid blends containing 1, 2.5, and $5 \mathrm{wt} \%$ of each ionic liquid are studied using a block-on-flat reciprocating tribometer and the test results are compared to commercially-available, fully-formulated lubricant. Results showed that the addition of the ionic liquids to the coffee bean oil reduces wear volume of the steel disks, and wear values achieved are comparable to that obtained when the commercially-available lubricant is used.
\end{abstract}

Keywords: ionic liquids; additives; wear; friction; biolubricants 


\section{Introduction}

The machines and devices that we use in our daily lives require energy to operate, and a significant portion of this energy is wasted through friction. In addition, wear is one of the major causes of mechanical failure of engineering equipment [1,2]. Most of these devices and machines need lubricants to reduce friction and wear, remove wear particles, minimize energy losses, evacuate the heat, and increase efficiency $[3,4]$. The world uses an average of 35 million tons per year of lubricants; this consumption is expected to increase $1.6 \%$ per year in the coming years [5]. The majority of these lubricants are mineral oil-based and are obtained from petroleum products. Petroleum-based lubricants are toxic and have poor biodegradability. It has been estimated that between 5 to 10 million tons of petroleum products affect the environment each year [3,6]. Environmental awareness and ever-growing restrictive regulations over contamination have increased the need for more environmentally-friendly lubricants. Due to their superior biodegradability and lower toxicity, vegetable oils are a good alternative to replace currently used mineral oils [7-10]. However, vegetable oils show low oxidation and thermal stability, poor low-temperature properties and narrow range of available viscosities [11,12] that limit their potential industrial application. Most of these drawbacks can be attenuated through the use of additives $[7,10,13,14]$.

In the last decade, Ionic Liquids (ILs) have emerged as high performance fluids due to their unique characteristics $[15,16]$. Their high thermal stability, low vapor pressure, non-flammability, non-volatility, high viscosity, broad liquid range, high ionic conductivity, wide electrochemical window, and miscibility with organic compounds make them ideal candidates for many engineering applications. ILs are salts with melting points lower than $100{ }^{\circ} \mathrm{C}$; and are usually composed of an organic cation and a weakly coordinating anion. In addition to the above-mentioned properties, ILs have the ability to form highly-ordered absorbed layers [17,18] on metal surfaces, reducing friction and wear of mechanical components. The use of RTILs as neat lubricants was first reported in 2001 [19]. Since then, ILs have emerged as promising advanced lubricants, not only as neat lubricants [20-22], but also as lubricant additives [23-27]. Most of the ILs used today in lubrication are composed of halogen-containing anions. It is well known that these anions will decompose in presence of water, liberating highly toxic and corrosive species $[21,28]$. Therefore, there is an urgent need to investigate the lubricating ability of halogen-free RTILs to avoid these negatives effects.

In this study, the tribological behavior of two phosphonium-based ILs, a fluorinated IL whose anion has shown excellent lubricating results of steel-steel contacts [29,30]: trihexyltetradecylphosphonium bis(trifluoromethylsulfonyl) amide [THTDP][NTf2] and a halogen-free IL: trihexyltetradecylphosphonium decanoate [THTDP][Deca], are investigated as additives of a coffee bean oil in steel-steel contact. Coffee bean oil-IL blends containing between $0 \mathrm{wt} \%$ and $5 \mathrm{wt} \%$ of each IL are investigated using a block-on-flat reciprocating tribometer and the test results are compared to commercially-available, fully-formulated lubricant.

\section{Materials and Methods}

\subsection{Coffee Bean Oil}

Coffee is one of the largest commodity products produced worldwide with an annual production of 8 million tons per year [31]. The consumption of coffee worldwide which is increasing yearly 
produces substantial quantities of spent coffee grounds (SCG) which can be problematic for disposal. Microbial decomposition of SCG is a high oxygen demand process (such as in landfills) and can produce residual caffeine, tannins, and polyphenolic contaminants to the environment [32].

The Rochester Institute of Technology (RIT) campus coffeehouses and dining halls produce more than $9000 \mathrm{~kg}$ of spent coffee grounds per year (Enid Cardinal, personal communication) of which $90 \%$ is disposed of in the garbage which ultimately ends up in various landfills. Thus, the use of spent coffee grounds (SCG) as a feedstock for coffee oil which can be tested as a lubricating oil may be an attractive alternative to trash disposal and ultimate shipment to Western New York landfills.

In this study, SCG were collected from various coffee houses on the RIT campus. The grounds were initially spread into a thin layer in various bins and partially dried in a greenhouse. Before oil extraction the partially dried SCG were further dried to remove any water by exposing the grounds to $85^{\circ} \mathrm{C}$ for $3-4 \mathrm{~h}$ in a drying oven. The oil was extracted from the SCG by taking $200 \mathrm{~g}$ of dried SCG and adding this to $600 \mathrm{~mL}$ of hexane. The mixture was allowed to shake at 200-250 rpm at room temperature for $24 \mathrm{~h}$. After $24 \mathrm{~h}$ the hexane fraction was collected by filtration and the hexane was removed by rotary evaporation under reduced pressure. The collected oil was then stored at room temperature until used.

\subsection{Ionic Liquids}

Ionic Liquids used in this study were commercially available from Sigma-Aldrich (St. Louis, MO, USA). Their molecular structure, name, and abbreviation (code) are shown in Table 1. Both ILs have identical cations with varying anion structures.

Table 1. Molecular structure, name, and abbreviation of ILs used in this study.

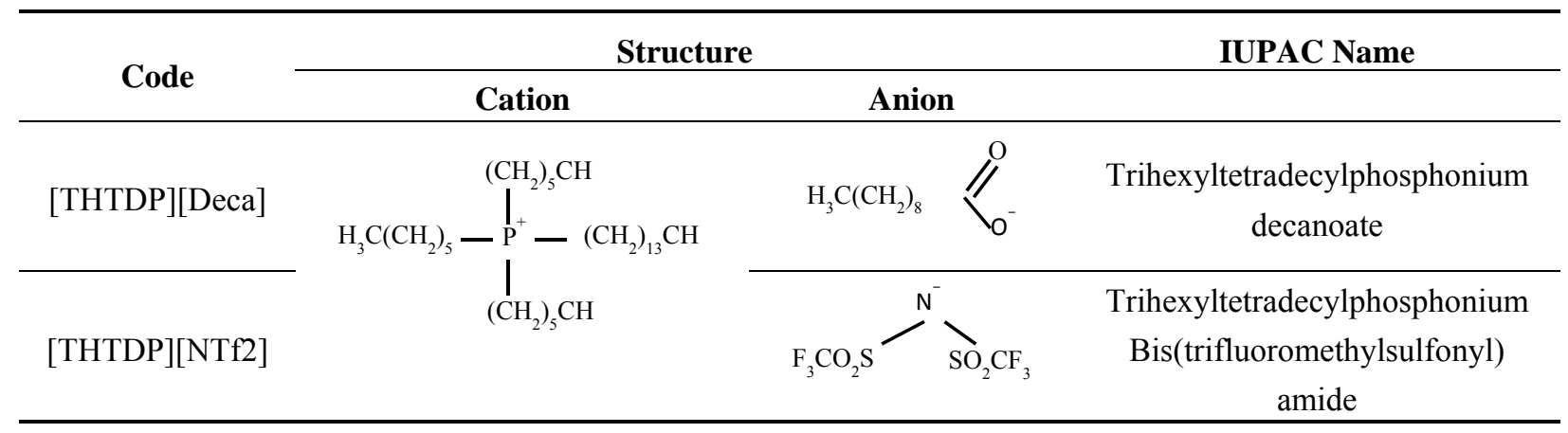

\subsection{Tribological Experiments}

AISI 52100 steel flat disks (19 mm diameter, 7 mm thickness, 243 hardness $\mathrm{HV}$, Roughness $\mathrm{Ra}=0.01 \mu \mathrm{m}$ ) were tested in a ball-on-flat reciprocating tribometer against AISI 420C steel balls $(1.5 \mathrm{~mm}$ spherical diameter, 690 hardness HV). Tribological tests were carried out at room temperature and under a normal load of $2 \mathrm{~N}$ (1.92 GPa maximum Hertzian pressure), $2 \mathrm{~mm}$ amplitude, $288 \mathrm{~m}$ sliding distance and $10 \mathrm{~Hz}$ oscillation frequency. Friction coefficients were continuously recorded with sliding distance. Mean friction coefficients and wear factors were obtained after three tests under the same conditions. Volume loss $\left(\mathrm{V}_{\mathrm{f}}\right)$ was determined by image analysis after 45 wear track width $\left(\mathrm{W}_{\mathrm{t}}\right)$ measurements for each test, according to Equation (1) [33]: 


$$
V_{f}=L_{s}\left[R_{f}^{2} \times \sin ^{-1}\left(\frac{W_{t}}{2 \times R_{f}}\right)-\left(\frac{W_{t}}{2}\right)\left(\frac{R_{f}}{h_{f}}\right)\right]+\frac{\pi}{3}\left(3 R_{f}-h_{f}\right)
$$

where Ls is stroke length, $\mathrm{R}_{\mathrm{f}}$ is the radius of AISI $420 \mathrm{C}$ steel ball, and $\mathrm{h}_{\mathrm{f}}$ is the wear depth given by Equation (2):

$$
h_{f}=R_{f}-\sqrt{R_{f}^{2}-\frac{W_{t}^{2}}{4}}
$$

Lubricating mixtures were prepared by adding 1, 2.5, $5 \mathrm{wt} \%$ ratio of ILs to the coffee bean oil (CB) and were compared to a commercially-available, fully-formulated, wind turbine gearbox lubricant (Mobilgear SHC XMP 320). Before each test, steel disks were covered with $2 \mathrm{~mL}$ of the lubricant, and no additional lubricant was added during the test. Optical micrographs of wear track were obtained using an Olympus BX60M optical microscope and wear track profiles using a Taylor-Hobson profilometer. SEM images were obtained using an AMRAY 1830 scanning electron microscope.

\subsection{Viscosity, Density, and Thermal Stability of Lubricants}

Densities at room temperature were determined by weighing a known volume. Viscosities at $40{ }^{\circ} \mathrm{C}$ and $100{ }^{\circ} \mathrm{C}$ were obtained using a Brookfield DV II+ viscometer with a small sample attachment. Thermogravimetric analysis (TGA) was carried out on a TA Instruments TGA-2950 at a $10{ }^{\circ} \mathrm{C} / \mathrm{min}$ heating rate in a nitrogen atmosphere.

\subsection{Wettability of Lubricants}

Contact angles of the lubricants on AISI 52100 steel surface to compare their wetting performance were measured using a Ramé-Hart advanced goniometer (p/n 500-00-15) with U1 series camera. All tests were run at $50 \pm 5{ }^{\circ} \mathrm{C}$, using a Ramé-Hart Environmental Chamber (p/n 100-70-00). As illustrated in Figure 1, a high contact angle indicates poor affinity between the lubricant and surface, and a low contact angle indicates good affinity [34].

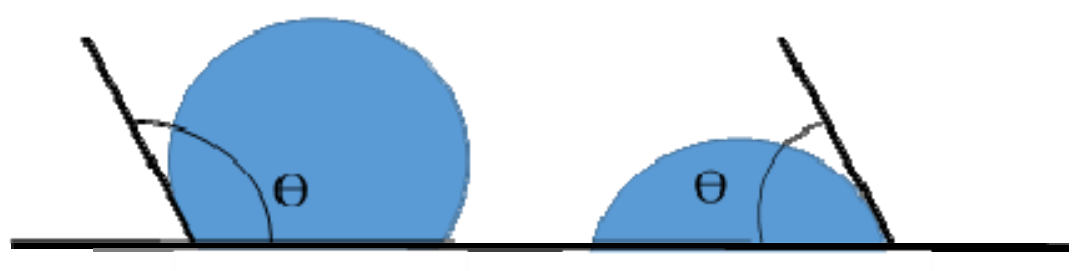

Poor Wettability Good Wettability

Figure 1. Contact angle to determine affinity between lubricants and the surface. 


\section{Results and Discussion}

\subsection{Viscosity, Density, and Thermal Stability of the Lubricants}

The density at $23{ }^{\circ} \mathrm{C}$ and kinematic viscosity at $40{ }^{\circ} \mathrm{C}$ and $100{ }^{\circ} \mathrm{C}$ of the lubricants used in this study are listed in Table 2. MG and CB have similar densities at $23^{\circ} \mathrm{C}$. The addition of the [THTDP][Deca] and [THTDP][NTf2] slightly increased the density of the mixtures. As can be seen in Table 2, MG is much more viscous than $\mathrm{CB}$ and $\mathrm{CB}$ mixtures, regardless of the measuring temperature. In general, adding the ILs to $\mathrm{CB}$ increases the viscosity of the $\mathrm{CB}$ at both temperatures.

Table 2. Density and viscosity values of the lubricants.

\begin{tabular}{|c|c|c|c|}
\hline \multirow{2}{*}{ Lubricant } & \multirow{2}{*}{$\begin{array}{c}\text { Density at } 23{ }^{\circ} \mathrm{C} \\
\left(\mathrm{g} / \mathrm{cm}^{3}\right)\end{array}$} & \multicolumn{2}{|c|}{ Kinematic Viscosity (cSt) } \\
\hline & & $40{ }^{\circ} \mathrm{C}$ & $100{ }^{\circ} \mathrm{C}$ \\
\hline MG & 0.86 & 335 & 38.3 \\
\hline $\mathrm{CB}$ & 0.85 & 53.5 & 9.4 \\
\hline $\mathrm{CB}+1 \%[\mathrm{THTDP}][\mathrm{Deca}]$ & 0.87 & 88.5 & 12.6 \\
\hline $\mathrm{CB}+2.5 \%[\mathrm{THTDP}][$ Deca $]$ & 0.86 & 148.3 & 19.2 \\
\hline $\mathrm{CB}+1 \%[\mathrm{THTDP}][\mathrm{NTf} 2]$ & 0.87 & 61.6 & 10.5 \\
\hline $\mathrm{CB}+2.5 \%$ [THTDP][NTf2] & 0.89 & 174.1 & 21.3 \\
\hline
\end{tabular}

The thermal stabilities of the lubricants were studied using thermogravimetric analysis (TGA). Figure 2 shows the evolution of weight loss with temperature for the lubricants. From the figure, MG shows the highest thermal stability, where the lubricant does not reach $1 \%$ weight loss until a temperature of $300{ }^{\circ} \mathrm{C}$. All the lubricants containing $\mathrm{CB}$ has a two-step decomposition process. For these lubricants, degradation reaches $1 \%$ weight loss around $150{ }^{\circ} \mathrm{C}$.

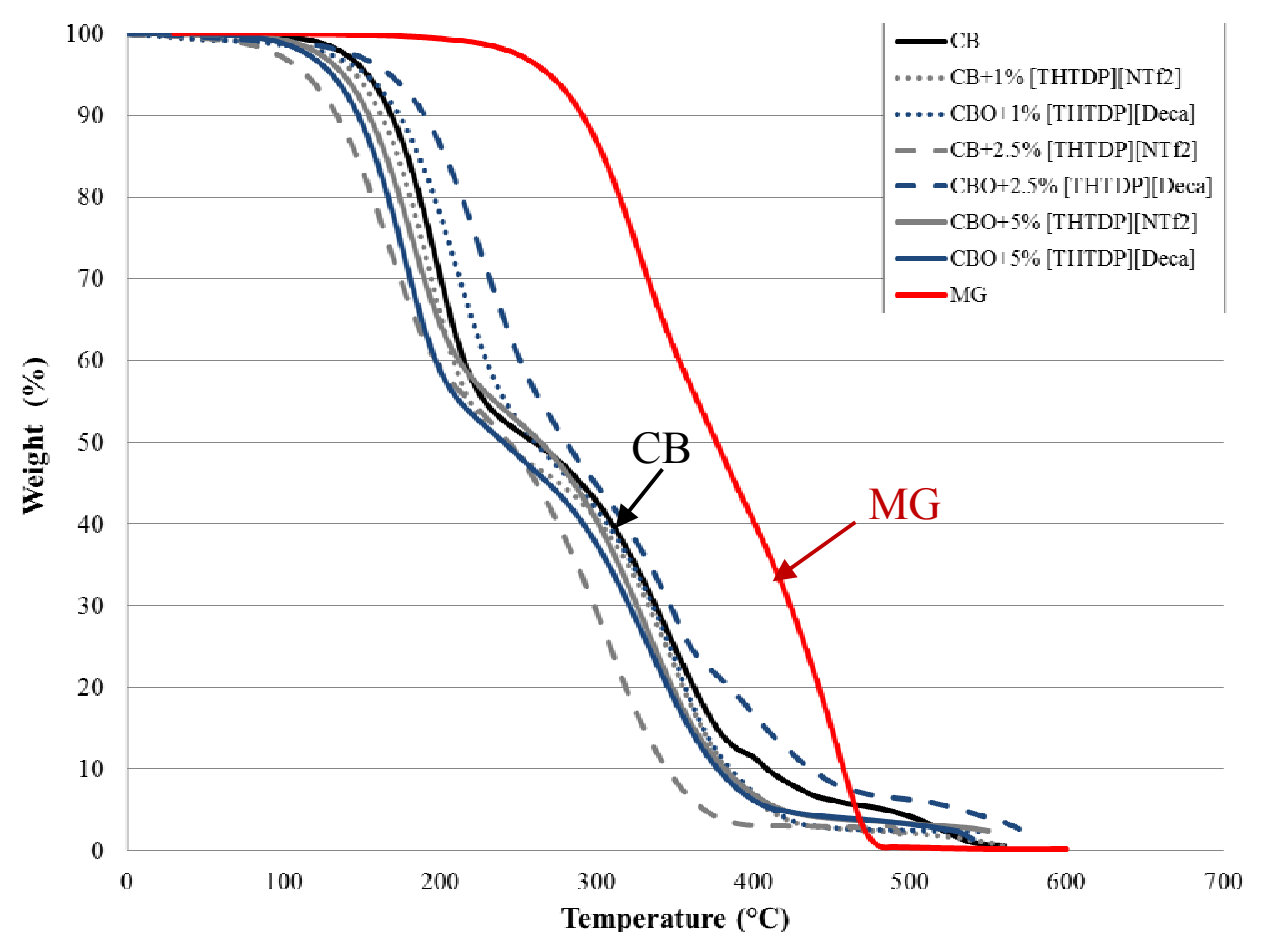

Figure 2. Weight loss vs. temperature TGA curves for the lubricants. 


\subsection{Wettability of Lubricants}

As mentioned in Section 2.5, the contact angle of the liquids on steel surface was measured to study the wetting ability of the lubricants. Figure 3 shows how the contact angle of the lubricants on steel surface is changing with time. MG is the lubricant with higher contact angle, which means poorer wettability. Adding more than $1 \mathrm{wt} \%$ of ILs to the $\mathrm{CB}$ reduces the contact angle of the mixtures, improving the wettability of the lubricant.

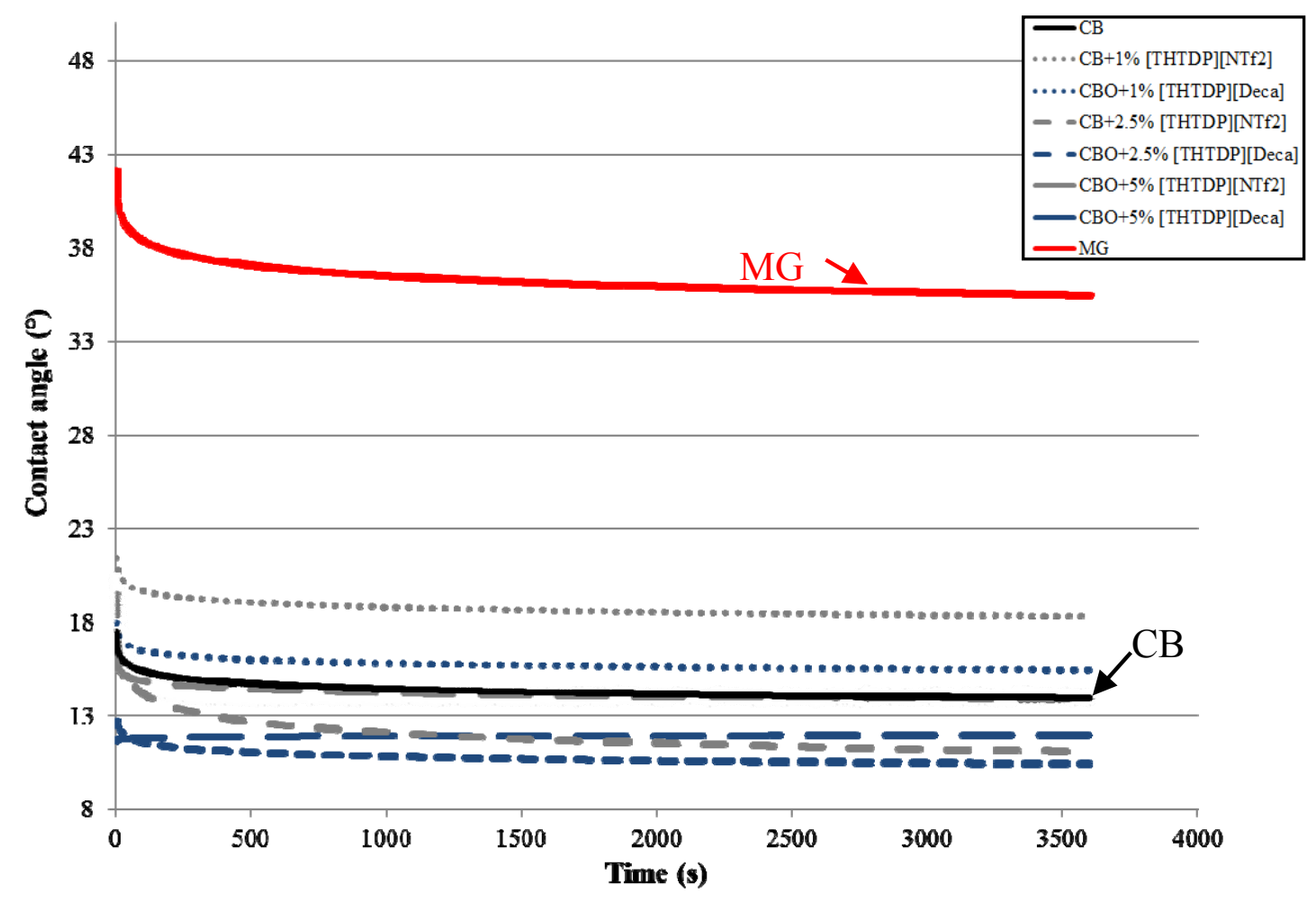

Figure 3. Contact angle $\left(^{\circ}\right)$ on steel surfaces of the lubricants vs. time.

\subsection{Tribological Properties}

Figure 4 shows friction coefficients for AISI 52100 steel disks after a ball-on-flat reciprocating test against AISI 420C steel balls lubricated with $\mathrm{MG}, \mathrm{CB}$, and $\mathrm{CB}+\mathrm{IL}$ mixtures. The friction performance of the $\mathrm{CB}$ is very similar to that of the MG. The addition [THTDP][Deca] to CB reduces the friction coefficient for steel, while adding [THTDP][NTf2] shows no significant effect on friction coefficient compared to that of $\mathrm{CB}$ without additive.

Real-time friction variation with sliding distance for $\mathrm{CB}, \mathrm{CB}+2.5 \%$ [THTDP] $\mathrm{NTf} 2]$ and $\mathrm{CB}+2.5 \%$ [THTDP][Deca] are shown in Figure 5. For CB, after an initial period of low friction (2000 s) a sharp increment is observed. Interestingly, when the ILs are used as additives, the friction coefficient remain constant for whole duration of the test, being lower for CB $+2.5 \%$ [THTDP][Deca]. 


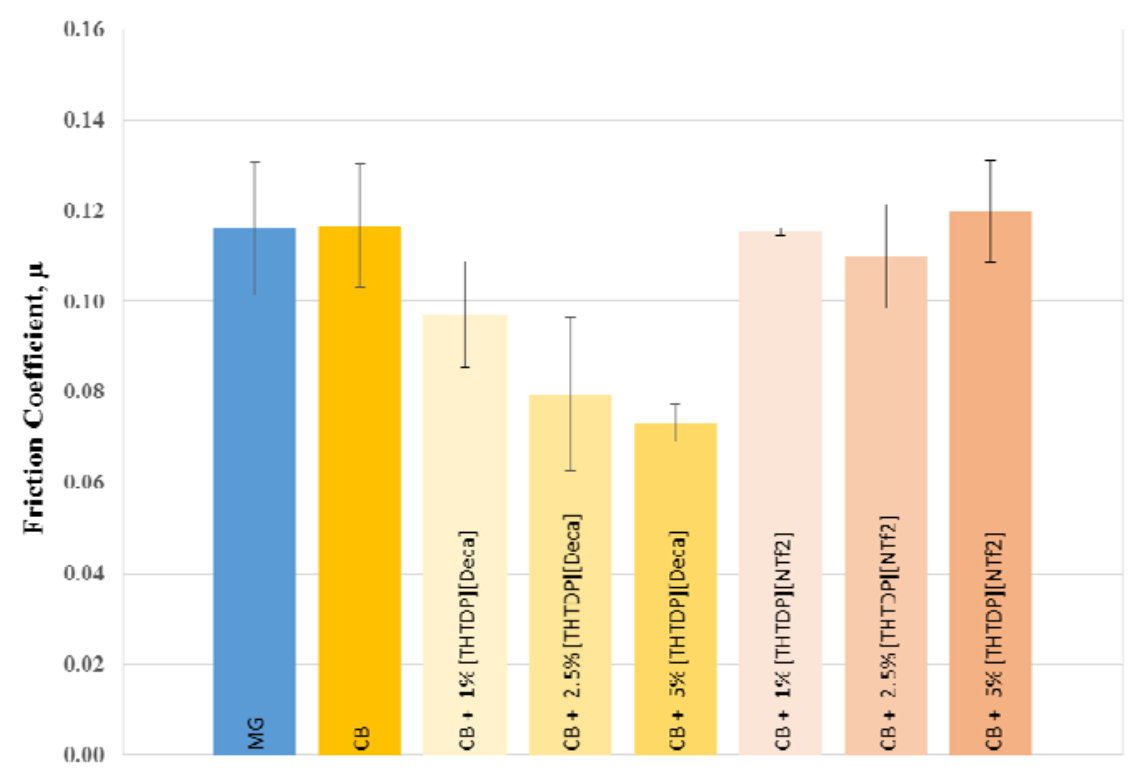

Figure 4. Friction coefficient using different lubricants.

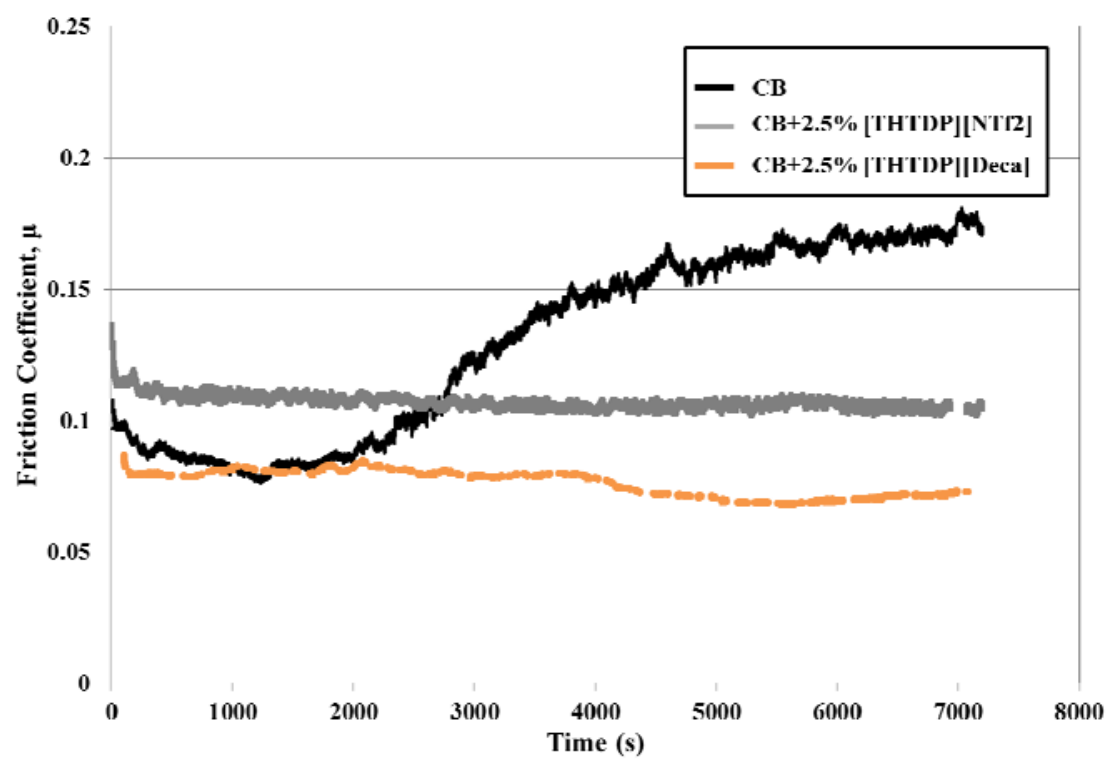

Figure 5. Friction curves for $\mathrm{CB}, \mathrm{CB}+2.5 \%$ [THTDP][NTf2] and $\mathrm{CB}+2.5 \%$ [THTDP][Deca].

Figure 6 shows wear volume of steel disk after tests lubricated with MG, CB, and CB + IL mixtures. As expected, when the test is lubricated with commercially-available MG, the wear volume of the steel disk is one order of magnitude smaller than that after a test lubricated with $\mathrm{CB}$. The use of ILs as additives of CB reduces the wear volume of the steel disks, and wear values achieved are comparable to that obtained when the commercially-available MG is used. While increasing additive concentration from 1 to $2.5 \mathrm{wt} \%$ has no significant effect on the lubricating ability of the ILs, the addition of $5 \mathrm{wt} \%$ shows an increase in the wear volume when both ILs are used. These results are in agreement with previous studies [24,35] that showed that increasing the concentration of ILs results in an increase of tribocorrosion reactions between the IL and metal surfaces and, therefore, an increase in the wear volume loss. [THTDP][NTf2] showed slightly better performance than [THTDP][Deca] under the conditions studied. 


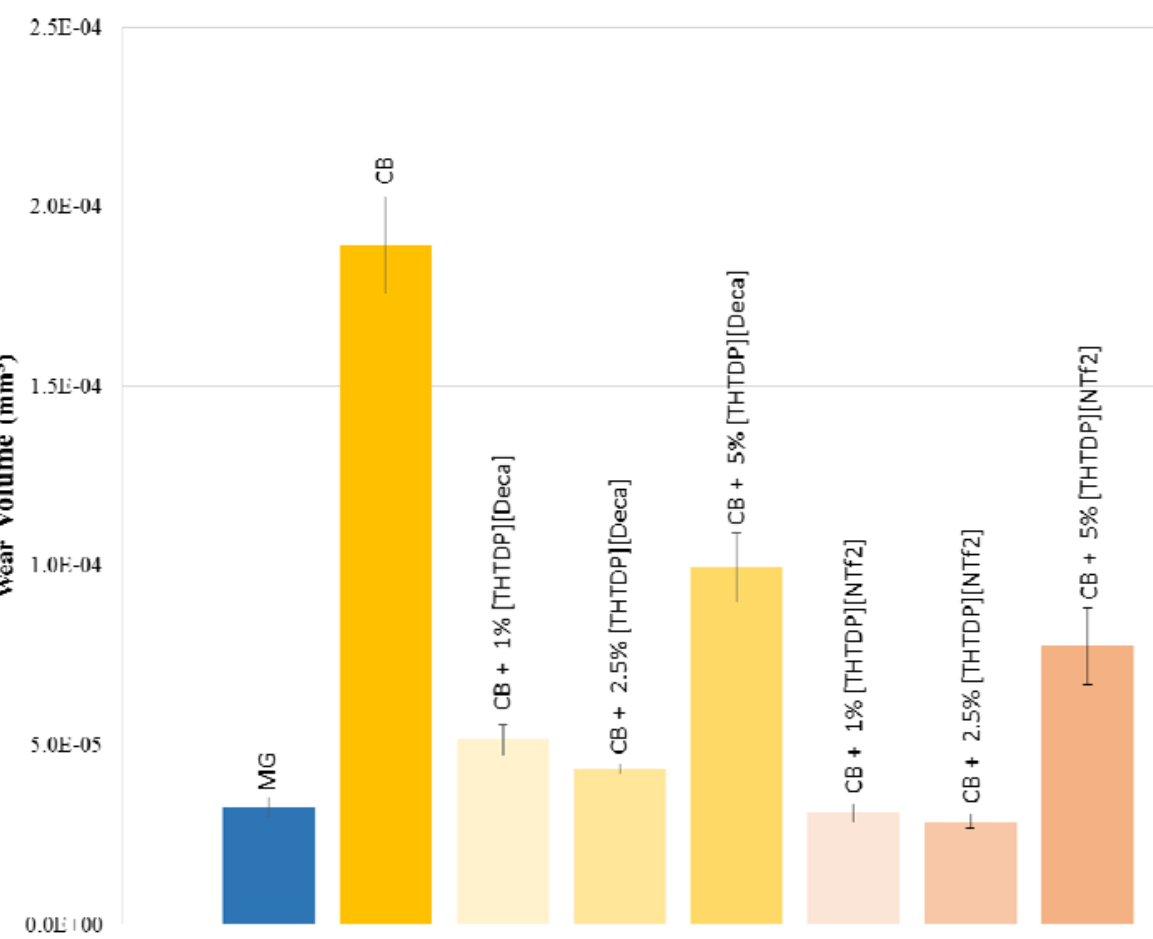

Figure 6. Wear volumes of steel disks after tests lubricated with $\mathrm{MG}, \mathrm{CB}$, and $\mathrm{CB}+\mathrm{IL}$ mixtures.

Figure 7 shows the wear track profiles on steel disk after a test using CB, CB $+2.5 \%$ [THTDP][NTf2], and $\mathrm{CB}+2.5 \%$ [THTDP] [Deca]. As can be seen, the area of wear loss is clearly smaller when the additives are used. Additionally, the area of material deformed plastically reduces when the ILs, and particularly [THTDP][NTf2], are presented in the lubricant.

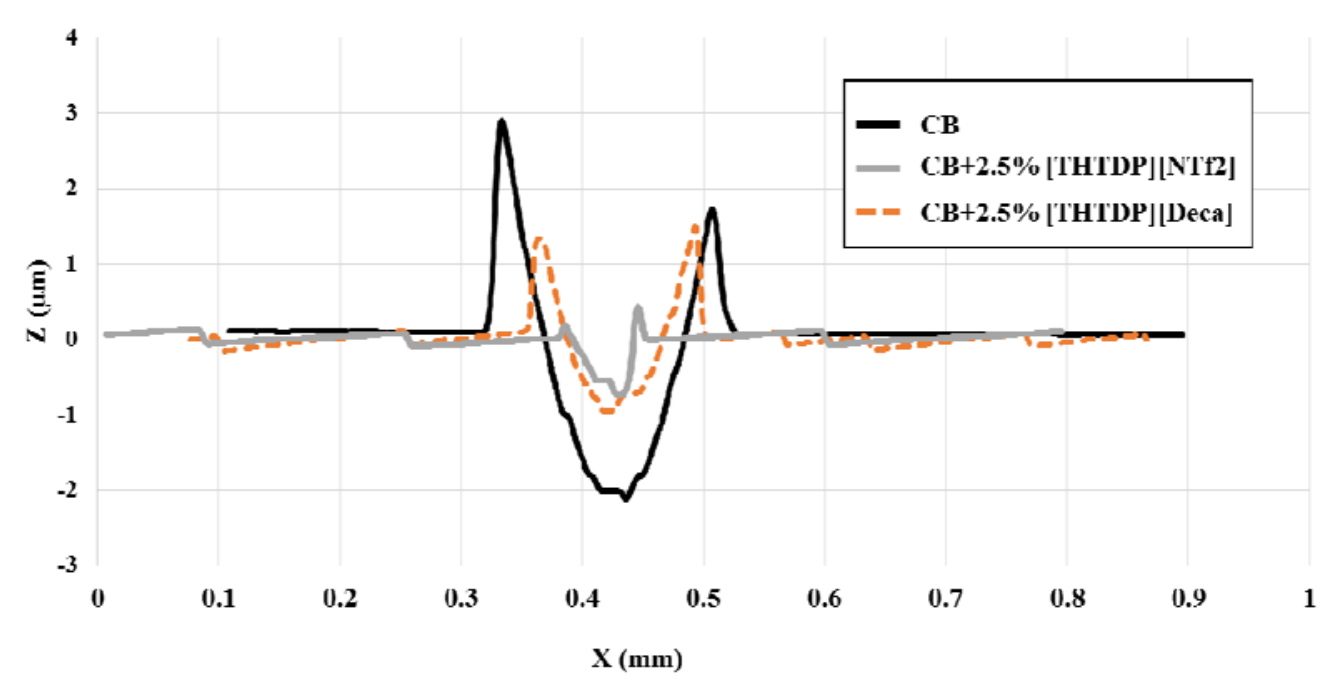

Figure 7. Wear track profiles on steel disks after a test lubricated with $\mathrm{CB}, \mathrm{CB}+2.5 \%$ [THTDP][NTf2], and CB + 2.5\% [THTDP][Deca].

Figures 8 and 9 show optical and SEM images of wear tracks on the steel disks after a test lubricated with $\mathrm{CB}, \mathrm{CB}+2.5 \%$ [THTDP][NTf2], and $\mathrm{CB}+2.5 \%$ [THTDP][Deca]. From the figure, wear tracks when ILs are used as additives of $\mathrm{CB}$ are much narrower and show a milder wear regime than that of a test lubricated with CB. Wear tracks for the three lubricants, but particularly when CB is 
used with no ILs, show lateral plastic flow inducing accumulation of material on the groove borders. Additionally, a presence of abrasive wear component is pointed out by the ploughed grooves inside the three wear tracks. The worn surface when ILs are not used as additives of CB, exhibited not only a higher amount of deformation but also fractures in the sub-surface and contacting surface, as can be seen under higher magnifications (Figure 9).

a)

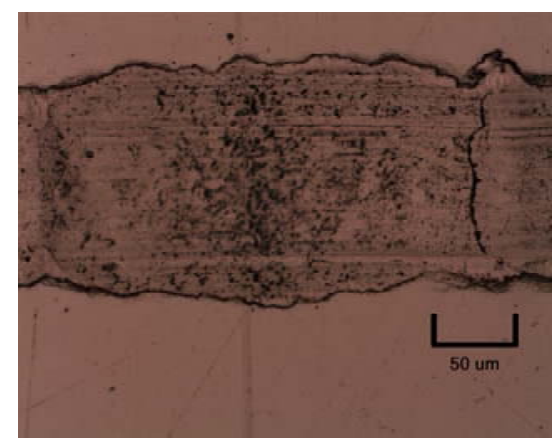

b)

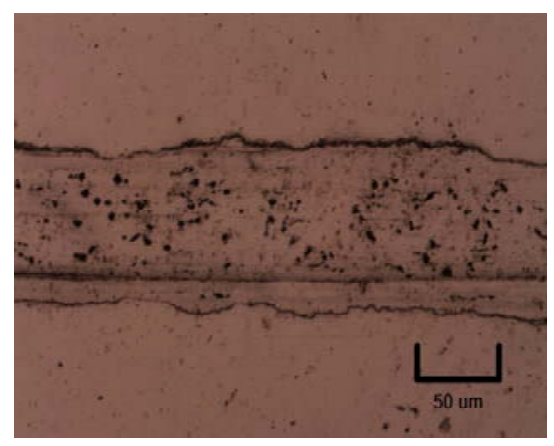

c)

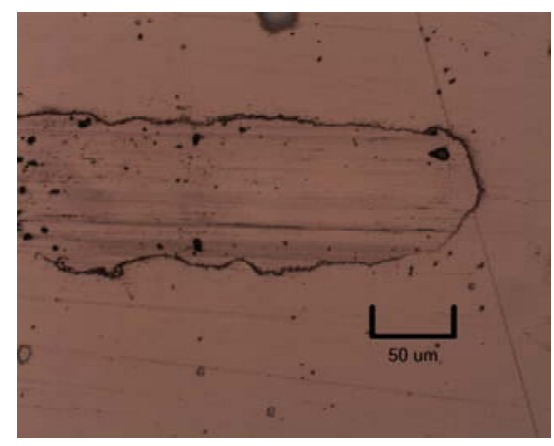

Figure 8. Optical micrographs of worn surfaces after a test lubricated with (a) $\mathrm{CB}$; (b) $\mathrm{CB}+2.5 \%$ [THTDP] $[\mathrm{NTf} 2]$, and (c) $\mathrm{CB}+2.5 \%$ [THTDP] $[$ Deca $]$.

a)

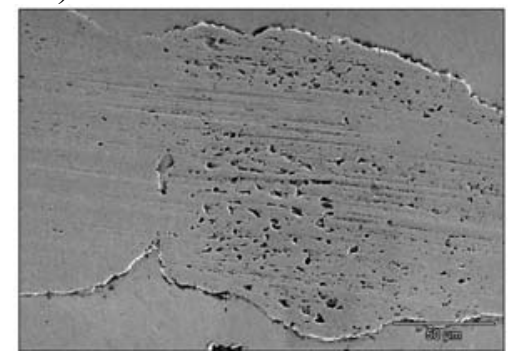

c)

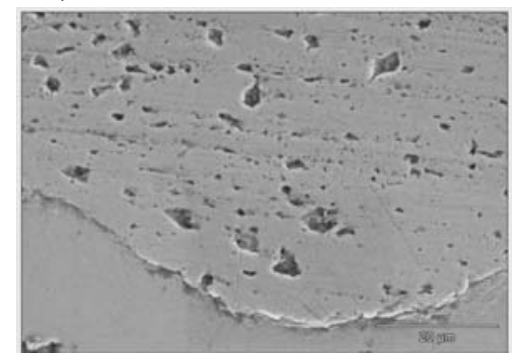

b)

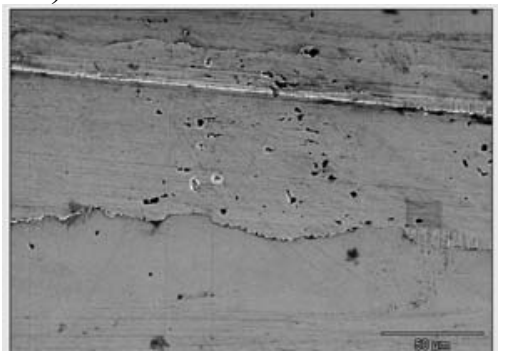

d)

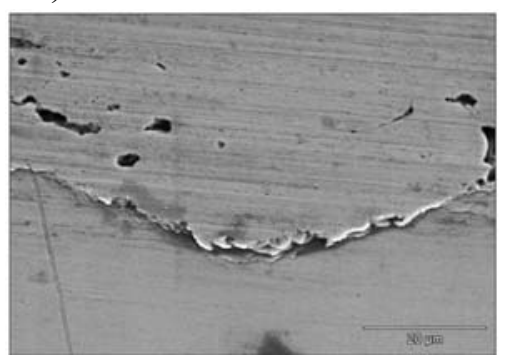

Figure 9. SEM micrographs of worn surfaces after a test lubricated with (a,c) $\mathrm{CB}$, (b,d) $\mathrm{CB}+2.5 \%$ [THTDP] $\mathrm{NTf} 2]$.

The good lubricating ability of the ILs can be attributed to the formation of a protective tribofilm on the metal surface $[23,25,36]$ with the active components present in the corresponding IL. The existence of this tribofilm is confirmed by the presence of fluorine (Figure 10) in wear debris when $\mathrm{CB}+2.5 \%$ [THTDP][NTf2] is used as the lubricant. The rest of the peaks of the spectrum in Figure 10, correspond to the alloys elements present in the steel disk. In addition, a peak of oxygen suggests an oxidative component of the wear mechanism. When the phosphonium cation is combined 
with a carboxylate anion, the tribofilm formed is very thin and contains as little phosphorus [29,37] that is hard to be detected by EDS.
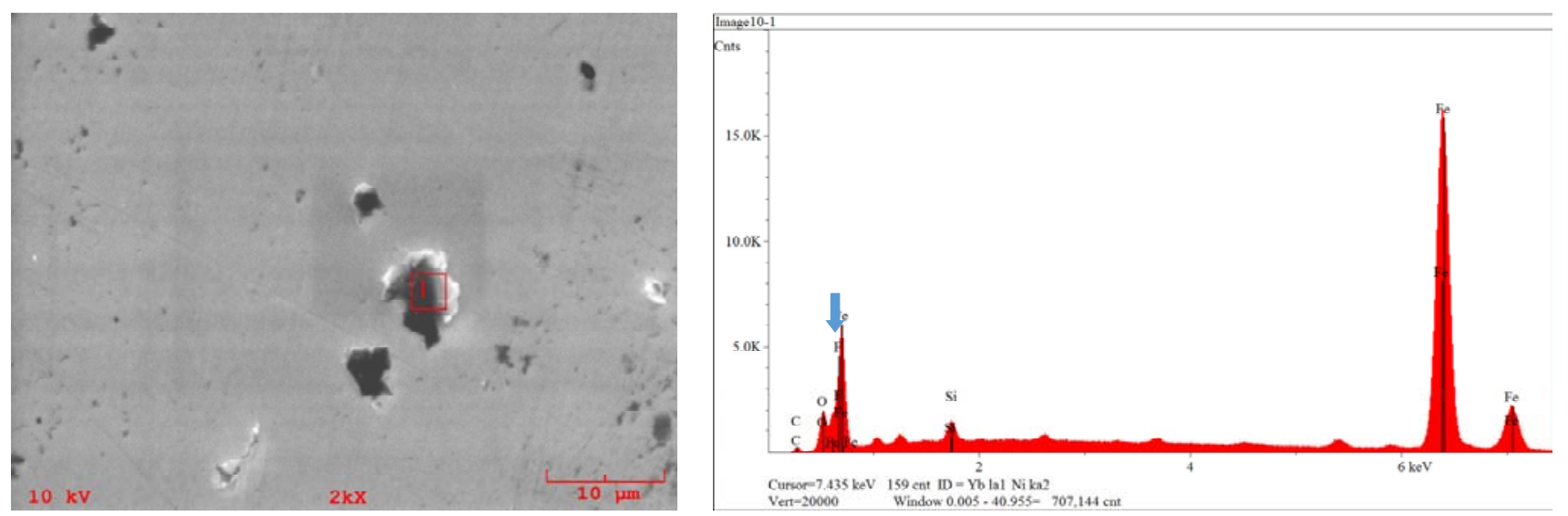

Figure 10. SEM micrograph and EDS spectrum of wear debris collected after a test lubricated with $\mathrm{CB}+2.5 \%$ [THTDP][NTf2].

\section{Conclusions}

This paper investigates the tribological behavior of two phosphonium-based ionic liquids (ILs) as additives of coffee bean oil (CB) in steel-steel contact. One, 2.5, $5 \mathrm{wt} \%$ ratio of Trihexyltetradecylphosphonium bis (trifluoromethylsulfonyl) amide ([THTDP][NTf2]) and Trihexyltetradecylphosphonium decanoate ([THTDP][Deca]) were added to CB and thermal stability, viscosity, wettability, and tribological performance of the mixtures were studied.

The addition of the ILs to the CB shows no significant effect on the density and thermal stability of the mixtures. However, adding the ILs to $\mathrm{CB}$ increases the viscosity of the $\mathrm{CB}$ at 40 and $100{ }^{\circ} \mathrm{C}$. $\mathrm{CB}$ and IL + CB mixtures show better wettability with steel surface than the commercially available, fully formulated lubricant.

The addition [THTDP][NTf2] to CB reduces the friction coefficient for steel, while adding [THTDP][Deca] shows no significant effect on friction coefficient compared to that of $\mathrm{CB}$ without additive. The use of ILs as additives of CB reduces the wear volume of the steel disks, and wear values achieved are comparable to that obtained when the commercially available MG is used. While increasing additive concentration from 1 to $2.5 \mathrm{wt} \%$ has no significant effect on the lubricating ability of the ILs, the addition of $5 \mathrm{wt} \%$ shows an increase in the wear volume when both ILs are used. [THTDP][NTf2] showed slightly better performance than [THTDP][Deca] under the conditions studied. The improvement in the lubrication ability of the CBO when ILs are added, can be attributed to the formation of a protective film on the metal surfaces that reduces wear of the materials in contact.

Wear tracks after tests lubricated with $\mathrm{CB}$ and CB + IL mixtures, present plastic deformation and fracture characteristic of adhesive wear, which is much more pronounced when the ILs are not present. In addition, a presence of abrasive wear component is pointed out by the ploughed grooves inside the wear tracks. 


\section{Acknowledgments}

The authors wish to thank the financial support of the New York State Pollution and Prevention Institute. James Grace and Solomiya Vysochanska are grateful to the College of Engineering at Rochester Institute of Technology for 2015 undergraduate summer research scholarship.

\section{Author Contributions}

Jeffrey Lodge synthesized the CB. James Grace and Solomiya Vysochanska performed the experiments under the supervision of Patricia Iglesias All authors contributed equally to the design of the experiments and analysis of the data. Patricia Iglesias wrote the paper with cooperation of Jeffrey Lodge.

\section{Conflicts of Interest}

The authors declare no conflict of interest.

\section{References}

1. Maleque, M.A.; Salit, M.S. Materials Selection and Design; SpringerBriefs: Singapore, 2013.

2. Collings, J.A. Failure of Materials in Mechanical Design: Analysis, Prediction, Prevention; Wiley: Hoboken, USA, 1993.

3. Sripada, P.K.; Sharma, R.V.; Dalai, A.K. Comparative study of tribological properties of trimethylolpropane-based biolubricants derived from methyl oleate and canola biodiesel. Ind. Crop. Prod. 2013, 50, 95-103.

4. Rizvi, S.Q.A. A Comprehensive Review of Lubricant Chemistry, Technology, Selection and Design; ASTM: West Conshohocken, USA, 2009.

5. Nagendramma, P.; Kaul, S. Development of ecofriendly/biodegradable lubricants: An overview. Renew. Sustain. Energy Rev. 2012, 16, 764-774.

6. Erhan, S.Z.; Sharma, B.K.; Liu, Z.; Adhvaryu, A. Lubricant base stock potential of chemically modified vegetable oils. J. Agric. Food Chem. 2008, 56, 8919-8925.

7. Wang, A.; Chen, L.; Jiang, D.; Zeng, H.; Yan, Z. Vegetable oil-based ionic liquid microemulsion biolubricants: Effect of integrated surfactants. Ind. Crop. Prod. 2014, 62, 515-521.

8. Zulkifli, N.W.M.; Kalam, M.A.; Masjuki, H.H.; Yunus, R. Experimental analysis of tribological properties of biolubricant with nanoparticle additive. Procedia Eng. 2013, 68, 152-157.

9. Mobarak, H.M.; Niza Mohamad, E.; Masjuki, H.H.; Kalam, M.A.; al Mahmud, K.A.H.; Habibullah, M.; Ashraful, A.M. The prospects of biolubricants as alternatives in automotive applications. Renew. Sustain. Energy Rev. 2014, 33, 34-43.

10. Wang, A.; Chen, L.; Jiang, D.; Yan, Z. Vegetable oil-based ionic liquid microemulsions and their potential as alternative renewable biolubricant basestocks. Ind. Crop. Prod. 2013, 51, 425-429.

11. Fox, N.J.; Stachowiak, G.W. Vegetable oil-based lubricants-A review of oxidation. Tribol. Int. 2007, 40, 1035-1046.

12. Campanella, A.; Rustoy, E.; Baldessari, A.; Baltanás, M.A. Lubricants from chemically modified vegetable oils. Bioresour. Technol. 2010, 101, 245-254. 
13. Hwang, H.-S.; Adhvaryu, A.; Erhan, S.Z. Preparation and properties of lubricant basestocks from epoxidized soybean oil and 2-ethylhexanol. J. Am. Oil Chem. Soc. 2003, 80, 811-815.

14. Hwang, H.-S.; Erhan, S.Z. Modification of epoxidized soybean oil for lubricant formulations with improved oxidative stability and low pour point. J. Am. Oil Chem. Soc. 2001, 78, 1179-1184.

15. Bermúdez, M.D.; Carrion, F.J.; Iglesias, P.; Jiménez, A.E.; Martínez-Nicolás, G.; Sanes, J. Ionic liquids interactions with materials surfaces applications in tribology and nanotechnology. MRS Proc. 2008, 1082, doi:10.1557/PROC-1082-Q07-02.

16. Reeves, C.J.; Garvey, S.; Menezes, P.; Dietz, M.; Jen, T.C.; Lowell, M.L. Tribological performance of environmentally friendly ionic liquid lubricants. In Proceedings of the ASME/STLE 2012 International Joint Tribology Conference, Denver, CO, USA, 7-10 October, 2012; ASME: Denver, CO, USA, 2012; pp. 7-9.

17. Minami, I. Ionic liquids in tribology. Molecules 2009, 14, 2286-2305.

18. Kamimura, H.; Kubo, T.; Minami, I.; Mori, S. Effect and mechanism of additives for ionic liquids as new lubricants. Tribol. Int. 2007, 40, 620-625.

19. Ye, C.; Liu, W.; Chen, Y.; Yu, L. Room-temperature ionic liquids: A novel versatile lubricant. Chem. Commun. 2001, 21, 2244-2245.

20. Qu, J.; Truhan, J.J.; Dai, S.; Luo, H.; Blau, P.J. Ionic liquids with ammonium cations as lubricants or additives. Tribol. Lett. 2006, 22, 207-214.

21. Totolin, V.; Minami, I.; Gabler, C.; Dörr, N. Halogen-free borate ionic liquids as novel lubricants for tribological applications. Tribol. Int. 2013, 67, 191-198.

22. García, A.; González, R.; Hernández Battez, A.; Viesca, J.L.; Monge, R.; Fernández-González, A.; Hadfield, M. Ionic liquids as a neat lubricant applied to steel-steel contacts. Tribol. Int. 2014, 72, $42-50$.

23. Jiménez, A.E.; Bermúdez, M.D. Short alkyl chain imidazolium ionic liquid additives in lubrication of three aluminium alloys with synthetic ester oil. Tribol. Mater. Surf. Interfaces 2012, 6, 109-115.

24. Jiménez, A.E.; Bermúdez, M.D.; Iglesias, P.; Carrión, F.J.; Martínez-Nicolás, G. 1-N-alkyl-3-methylimidazolium ionic liquids as neat lubricants and lubricant additives in steel-aluminium contacts. Wear 2006, 260, 766-782.

25. Jiménez, A.E.; Bermúdez, M.D.; Iglesias, P. Lubrication of Inconel 600 with ionic liquids at high temperature. Tribol. Int. 2009, 42, 1744-1751.

26. Anand, M.; Hadfield, M.; Viesca, J.L.; Thomas, B.; Hernández Battez, A.; Austen, S. Ionic liquids as tribological performance improving additive for in-service and used fully-formulated diesel engine lubricants. Wear 2015, 334-335, 67-74.

27. Viesca, J.L.; García, A.; Hernández Battez, A.; González, R.; Monge, R.; Fernández-González, A.; Hadfield, M. FAP' anion ionic liquids used in the lubrication of a steel-steel contact. Tribol. Lett. 2013, 52, 431-437.

28. Espinosa, T.; Sanes, J.; Bermúdez, M.D. Halogen-free phosphonate ionic liquids as precursors of abrasion resistant surface layers on AZ31B magnesium alloy. Coatings 2015, 5, 39-53.

29. Monge, R.; González, R.; Hernández Battez, A.; Fernández-González, A.; Viesca, J.L.; García, A.; Hadfield, M. Ionic liquids as an additive in fully formulated wind turbine gearbox oils. Wear 2015, 328-329, 50-63. 
30. Mahrova, M.; Pagano, F.; Pejakovic, V.; Valea, A.; Kalin, M.; Igartua, A; Tojo, E. Pyridinium based dicationic ionic liquids as base lubricants or lubricant additives. Tribol. Int. 2015, 82, 245-254.

31. International Coffee Organitation. Annual Review 2011/2012. Avilable online: http:// www.ico.org/show_news.asp?id=319 (accessed on July 2015).

32. Silva, M.A.; Nebra, S.A.; Machado Silva, M.J.; Sanchez, C.G. The use of biomass residues in the Brazilian soluble coffee industry. Biomass Bioenerg. 1998, 14, 457-467.

33. Qu, J.; Truhan, J.J. An efficient method for accurately determining wear volumes of sliders with non-flat wear scars and compound curvatures. Wear 2006, 261, 848-855.

34. Lawes, S.D.; Hainsworth, S.V.; Blake, P.; Ryder, K.S.; Abbott, A.P. Lubrication of steel/steel contacts by choline chloride ionic liquids. Tribol. Lett. 2010, 37, 103-110.

35. Iglesias, P.; Mcnabb, K.B. Improving wear performance of wind turbine gearboxes using ionic liquids as additives of lubricants. In Proceedings of the VIII Iberian Conference on Tribology Ibertrib 2015, Cartagena, Colombia, 18-19 June 2015; pp. 23-28.

36. Minami, I.; Inada, T.; Sasaki, R.; Nanao, H. Tribo-chemistry of phosphonium-derived ionic liquids. Tribol. Lett. 2010, 40, 225-235.

37. Zhou, Y.; Dyck, J.; Graham, T.W.; Luo, H.; Leonard, D.N.; Qu, J. Ionic liquids composed of phosphonium cations and organophosphate, carboxylate, and sulfonate anions as lubricant antiwear additives. Langmuir 2014, 30, 13301-13311.

(C) 2015 by the authors; licensee MDPI, Basel, Switzerland. This article is an open access article distributed under the terms and conditions of the Creative Commons Attribution license (http://creativecommons.org/licenses/by/4.0/). 